\title{
SÍNTESE E CARACTERIZAÇÃo DE PLLA e P(LLA-co-CL) OBTIDO EM REAÇÕES DE POLIMERIZAÇÃO EM SOLUÇÃO.
}

\author{
E. C. de Souza ${ }^{1}$ K. W. Miranda ${ }^{1,2}$, M. A. T Duarte ${ }^{1}$ e S. H. Pezzin ${ }^{2}$ \\ ${ }^{1}$ Centro Universitário Tupy - UNISOCIESC, Bacharelado em Engenharia Química \\ 2 Universidade do Estado de Santa Catarina - UDESC, Programa de Pós-graduação em \\ Ciência e Engenharia de Materiais \\ E-mail para contato: eduardacanni@gmail.com
}

RESUMO - Os polímeros biodegradáveis são uma das principais alternativas aos polímeros derivados do petróleo, entre eles destacam-se a poli( $\varepsilon$-caprolactona) (PCL) e o poli(l-ácido lático) (PLLA). Neste estudo, foi realizada a síntese do PLLA e do P(LLA-co-CL) nas seguintes frações mássicas: 100/0, 95/5, 90/10 e 80/20, todas as amostras foram sintetizadas utilizando a técnica de polimerização em solução e os mesmos parâmetros racionais. $\mathrm{O}$ polímero e os copolímeros foram caracterizados por $\mathrm{RMN}-\mathrm{C}^{13}$, $\mathrm{RMN}-\mathrm{H}^{1}$, DSC, e os monômeros foram caracterizados TG. Somente a amostra que contêm fração igual $20 \%$ de $\varepsilon$ caprolactona $(\mathrm{CL})$ formou o copolímero este fato foi evidenciado nas análises de RMN e pode ser associado com a baixa temperatura de volatilização da $\mathrm{CL}$ (aprox. $60^{\circ} \mathrm{C}$ ), enquanto que a síntese é conduzida à $120^{\circ} \mathrm{C}$. As curvas de DSC indicam que apesar de a CL não reagir com o 1-lactídeo (LLA) em proporção menor que $20 \%$ em massa, a mesma interfere nas propriedades físicas do material.

\section{INTRODUÇÃO}

De acordo com Raquez et al. (2013) e Brito et al. (2010), os polímeros biodegradáveis são alvo de estudos nas últimas décadas, pois estes servem como uma alternativa promissora para a substituição dos polímeros provenientes de fontes fósseis. Estes materiais podem ser obtidos a partir de matérias primas renováveis e degradam pela ação de microrganismos como bastérias, fungos e algas, gerando biomassa, água e $\mathrm{CO}_{2}$.

Segundo Lian et al. (2013), Minata et al. (2013) e Leite et al. (2010) no mercado, existem diversos polímeros biodegradáveis, entre eles, destacam-se o poli(l-ácido lático) e a poli( $\varepsilon$-caprolactona). Estes materiais possuem potencial para aplicações, na área farmacêutica como partículas para liberação controlada de medicamentos; na área biomédica como implantes e dispositivos médicos e em embalagens de rápida descartabilidade. $\mathrm{O}$ poli (1-ácido lático) PLLA é obtido a partir do seu monômero cíclico o l-lactídeo por reações de abertura de anel e tem como características: rigidez e fragilidade, mas também bicompatibilidade e comportamento termoplástico. A poli ( $\varepsilon$-caprolactona) PCL é um polímero não tóxico, semicristalino, biocompatível e possui baixo ponto de fusão e pode ser produzida através da abertura de anel do seu monômero a $\varepsilon$-caprolactona. Diferente do PLLA, a PCl é de origem sintética. A Figura 1 ilustra a estrutura química dos meros de ambos os polímeros. 
Figura 1 - Estrutura química do (a) poli(l-ácido láctico) e da (b) poli(e-caprolactona).<smiles>CCC1(C(=O)OC(C)C)CO1</smiles>

(a)

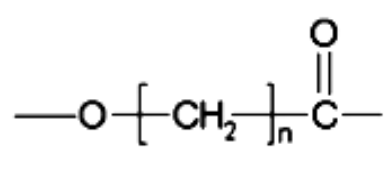

(b)

A obtenção de copolímeros destes monômeros pode dar origem a materiais que combinam estas propriedades. Quanto maior for a fração de CL no copolímero, maior poderá ser a flexibilidade e, além disso, o tempo de degradação irá variar conforme a fração de CL, quanto mais unidade CL, maior é o tempo requerido para a degradação. A Tabela 1 mostra algumas características para esses polímeros.

Tabela 1 - Propriedades físicas e tempo de degradação em solo para o PLLA e para a PCL.

\begin{tabular}{ccccc}
\hline Polímero & $\mathrm{T}_{\mathrm{m}}\left({ }^{\circ} \mathrm{C}\right)$ & $\mathrm{T}_{\mathrm{g}}\left({ }^{\circ} \mathrm{C}\right)$ & $\begin{array}{c}\text { Módulo de } \\
\text { elasticidade }(\mathrm{Gpa})\end{array}$ & $\begin{array}{c}\text { Tempo de } \\
\text { degradação } \\
\text { (meses })\end{array}$ \\
\hline $\begin{array}{c}\text { Poli(1- ácido láctico) } \\
\text { (PLLA) }\end{array}$ & $173-178$ & $60-65$ & $1,5-2,7$ & $12-18$ \\
\hline \begin{tabular}{c} 
Poli( $\begin{array}{c}\text { ( }- \text { caprolactona) } \\
\text { (PCL) }\end{array}$ \\
\hline
\end{tabular} & $58-63$ & 60 & $0,4-0,6$ & 24 \\
\hline
\end{tabular}

O P(LLA-co-CL) tende a ser mais flexível, devido a PCL possuir baixa temperatura de transição vítrea, $\mathrm{Tg}$ entre $-60 \mathrm{e}-70^{\circ} \mathrm{C}$, e baixa temperatura de fusão, cerca de $60^{\circ} \mathrm{C}$, mostrado por Torabinejad et al. (2014), isso significa que estrutura a estrutura da CL pode dar origem a mais regiões amorfas que o LLA pode originar.

Tanto os polímeros quanto os copolímeros podem ser sintetizados utilizando a técnica de polimerização em solução, onde é empregado o tolueno como solvente que proporciona melhor dissipação do calor reacional diminuindo a distribuição de massa molecular do produto. Esta polimerização ocorre por abertura de anel dos monômeros, utilizando octoato de estanho II como iniciador que requer grupos hidroxila para promover a reação.

O objetivo deste trabalho é obter o copolímero P(LLA-co-CL) em diferentes proporções mássicas por meio da técnica de polimerização em solução e caracterizá-los pelas técnicas de ressonância magnética nuclear de carbono $\left(\mathrm{RMN}-\mathrm{C}^{13}\right)$, ressonância magnética nuclear de hidrogênio $\left(\mathrm{RMN}-\mathrm{H}^{1}\right)$ e calorimetria exploratória diferencial (DSC).

\section{PROCEDIMENTO EXPERIMENTAL}

Os homopolímeros e copolímeros foram sintetizados de acordo com as proporções mássicas (Tabela 2). Os reagentes foram colocados em um balão de três bocas que estava acoplado a um condensador, um termômetro e a um fluxo de $\mathrm{N}_{2}$. O sistema foi aquecido a $120^{\circ} \mathrm{C}$ e sob agitação constante. Foram retiradas amostras após 2:30, 5, 7 e 12 horas de 
reação. A solução foi vertida em $200 \mathrm{~mL}$ de metanol para provocar a precipitação do polímero que foi filtrado e seco em estufa por 24 horas a $40^{\circ} \mathrm{C}$ e armazenado em dessecador.

Tabela 2 - Proporções mássicas para a obtenção dos homopolímeros e copolímeros.

\begin{tabular}{cccccc}
\hline Reagentes & $100 / 0(\mathrm{~g})$ & $95 / 05(\mathrm{~g})$ & $90 / 10(\mathrm{~g})$ & $80 / 20(\mathrm{~g})$ & $70 / 30(\mathrm{~g})$ \\
\hline 1-lactídeo & 50 & 47,5 & 45,0 & 40,0 & 35,0 \\
\hline$\varepsilon$-caprolactona & - & 2,5 & 5,0 & 10,0 & 15,0 \\
\hline Metanol & 0,0073 & 0,0073 & 0,0073 & 0,0073 & 0,0073 \\
\hline Sn $(\text { Oct })_{2}$ & 0,0078 & 0,0078 & 0,0078 & 0,0078 & 0,0078 \\
\hline Tolueno & 43,3 & 43,3 & 43,3 & 43,3 & 43,3 \\
\hline
\end{tabular}

As amostras de PLLA e dos copolímeros P(LLA-co-CL) foram submetidas à análise de espectroscopia de ressonância magnética nuclear de carbono (RMN-C ${ }^{13}$ ) em um espectrômetro Varian Mercury Plus, operando a $500 \mathrm{MHz}$, por 1 hora. Também foram realizadas análises de ressonância magnética nuclear de hidrogênio em um equipamento Bruker AC 200. Todas as amostras foram dissolvidas em clorofórmio deuterado $\left(\mathrm{CDCl}_{3}\right)$ e o tetrametilsilano (TMS) foi empregado como padrão interno e as análises foram todas realizadas a $294 \mathrm{~K}$.

As análises de calorimetria exploratória diferencial (DSC) do PLLA e dos copolímeros de PLLA-co-PCL foram realizadas em um equipamento TA Q50, onde foram armazenadas em um porta amostras de alumínio, sob atmosfera de $\mathrm{N}_{2}$ com fluxo de $40 \mathrm{~mL} / \mathrm{min}$. As amostras foram aquecidas de -90 a $200^{\circ} \mathrm{C}$, resfriadas novamente a -90 e aquecidas a $200^{\circ} \mathrm{C}$, a $10^{\circ} \mathrm{C} / \mathrm{min}$.

Também foram realizadas análises termogravimétricas (TG) para os monômeros 1lactídio e para $\varepsilon$-caprolactona em um equipamento TA Q20, operando $20-400^{\circ} \mathrm{C}$, a $10^{\circ} \mathrm{C} / \mathrm{min}$. As amostras foram condicionadas em um porta amostras de platina, sob atmosfera de $\mathrm{N}_{2}$ com um fluxo de $40 \mathrm{~mL} / \mathrm{min}$.

\section{RESULTADOS}

A Figura 2 ilustra a reação química entre os monômeros de l-lactídeo e a $\varepsilon$-caprolactona para a obtenção do copolímero P(LA-co-CL). As letras sobre a estrutura do copolímero indicam os sinais nos espectros de $\mathrm{RMN}-\mathrm{C}^{13}$, indicados na Tabela 3.

Figura 2 - Reação química para a obtenção do copolímeros P(LLA-co-CL).

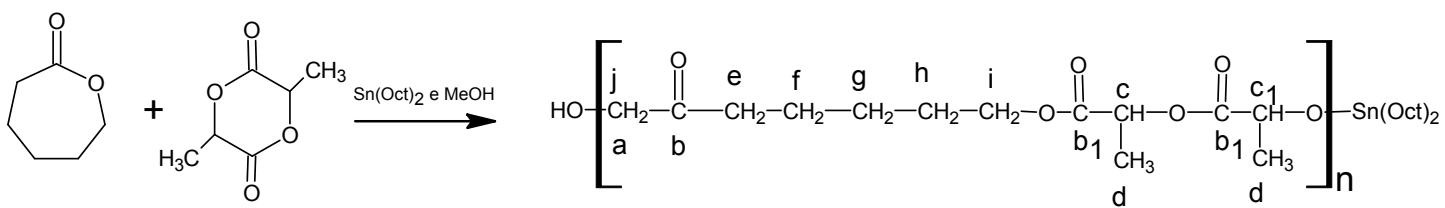

A amostra de PLLA (100\%) apresentou três sinais com deslocamento químico. O primeiro em 16,61 ppm referente ao carbono metílico; o segundo em 69,02 ppm referente ao carbono metilênio e o terceiro em 169,6 ppm referente ao carbono da carboníla. Os sinais estão representados na Figura 2 pelas letras b1, c e d, respectivamente. As sínteses 
alimentadas com até $15 \%$ do monômero $\varepsilon$-caprolactona não formaram copolímero e este fato pode ser comprovado pela ausência de sinais referentes à carbonila e aos grupos metilênicos deste monômero nos espectros de $\mathrm{RMN}-\mathrm{C}^{13}$. Os sinais foram determinados conforme proposto pela literatura elucidada também na Tabela 3.

Tabela 3 - Sinais de RMN-C ${ }^{13}$ para o PLLA e seus copolímeros P(LLA-co-CL) obtidos experimentalmente e comparados com a literatura.

\begin{tabular}{ccccccccc}
\hline \multicolumn{1}{c}{ LITERATURA } & \multicolumn{5}{c}{ EXPERIMENTAL } \\
\hline Sinal & $\begin{array}{c}\text { Castro, } \\
(2006)\end{array}$ & $\begin{array}{c}\text { Roa, et } \\
\text { al. } \\
(2010)\end{array}$ & $\begin{array}{c}\text { Chen, et } \\
\text { al. } \\
(2006)\end{array}$ & $100 / 0$ & $95 / 5$ & $90 / 10$ & $85 / 15$ & $80 / 20$ \\
\hline a & - & - & - & & & & & 16,75 \\
\hline b & 173,50 & 175 & - & & & & & 175,01 \\
\hline b1 & 169,60 & - & 169,53 & 169,6 & 169,6 & 169,6 & 169,60 & 169,59 \\
\hline c & 69,06 & - & 68,93 & 69,02 & 68,98 & 68,98 & 68.96 & 69,23 \\
\hline c1 & - & - & - & & & & & 69,02 \\
\hline d & 16 & - & 16,57 & 16,61 & 16,62 & 16,62 & 16,57 & 16,58 \\
\hline e & 64,14 & 65 & - & & & & & 62,46 \\
\hline f & 25 & 25 & - & & & & & 25,20 \\
\hline g & 24 & 24 & - & & & & & 24,56 \\
\hline h & 28 & 28 & - & & & & & 32,08 \\
\hline i & 33 & 34 & - & & & & \\
\hline j & - & - & - & & & & \\
\hline
\end{tabular}

A Figura 4 ilustra os espectros de $\mathrm{RMN}-\mathrm{H}^{1}$ para as amostras de PLLA e P(LLA-co-CL) $80 \%$, colaborando com os resultados de $\mathrm{RMN}-\mathrm{C}^{13}$, mostrando que somente a partir da alimentação de $20 \%$ do monômero $\varepsilon$-caprolactona é que houve a formação de um copolímero. A Tabela 4 reúne os deslocamentos químicos (sinal) para cada segmento de cadeia dos polímeros.

Figura 4 - Espectros de RMN-H ${ }^{1}$ para as amostras de (a) PLLA e (b) P(LLA-co-CL)

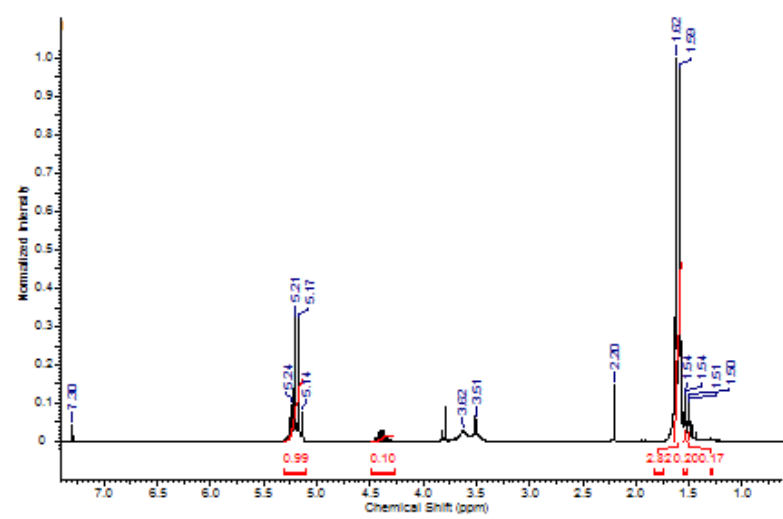

(a) PLLA

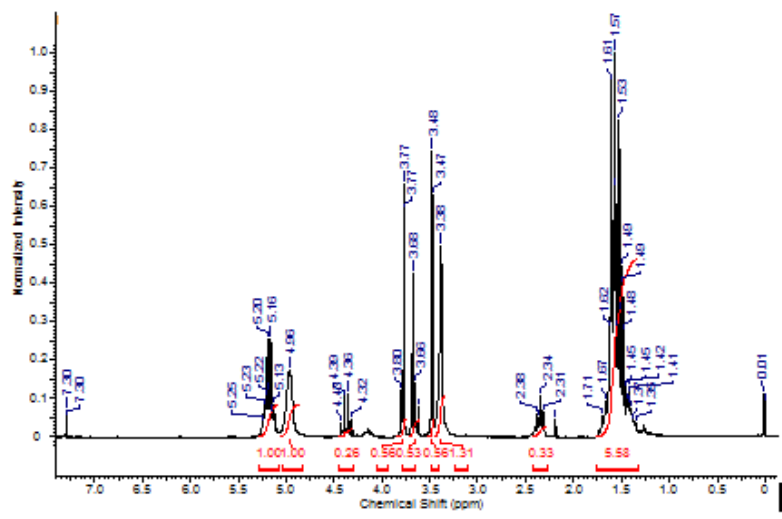

(b) PLLA-CO-PCL $80 \%$

Com a análise termogravimétrica apresentada na Figura 5, foi possível verificar que os monômeros sofrem perda de massa em $64^{\circ} \mathrm{C}$ para $\varepsilon$-caprolactona $(\mathrm{CL})$ e $104^{\circ} \mathrm{C}$ para Llactídeo (LLA). Confirmando que a temperatura utilizada na síntese $\left(120^{\circ} \mathrm{C}\right)$ é o suficiente 
para volatilizar as moléculas de CL e LLA, o qual dificulta a reatividade dos dois monômeros na fase líquida.

Figura 5 - Curvas da TG para os monômeros CL e LLA.

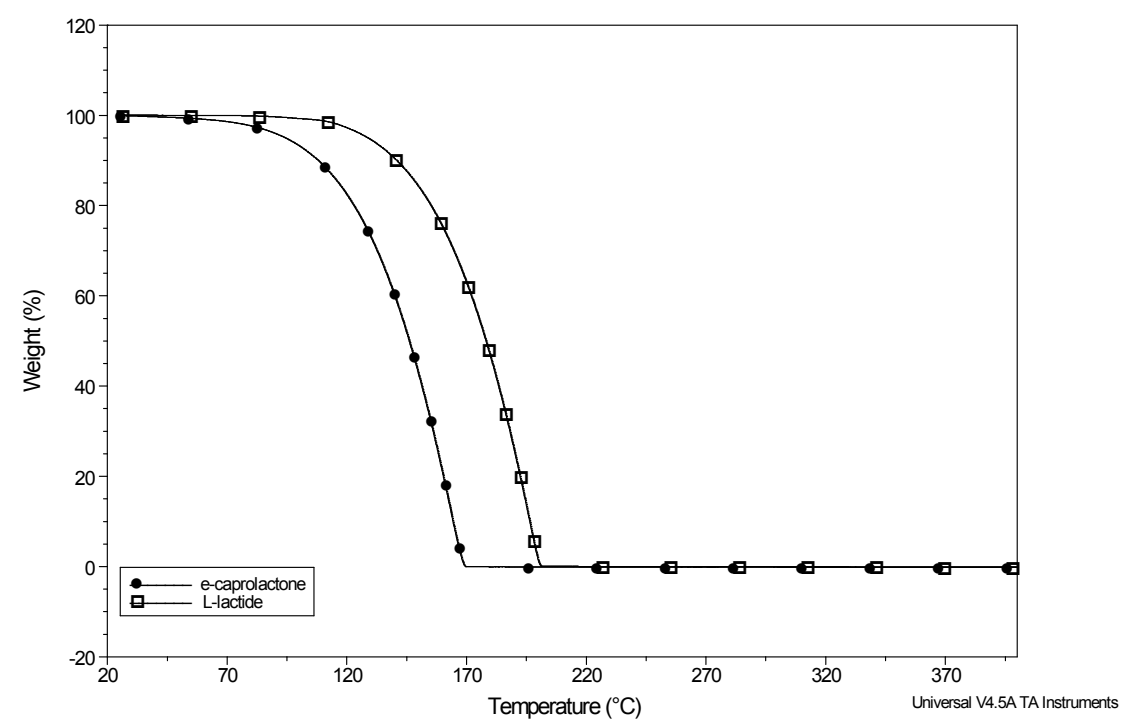

A Figura 6 ilustra os gráficos obtidos pela análise de DSC.

Figura 6 - Sobreposição das curvas de DSC das amostras de PLLA e PLLA-co-PCL.

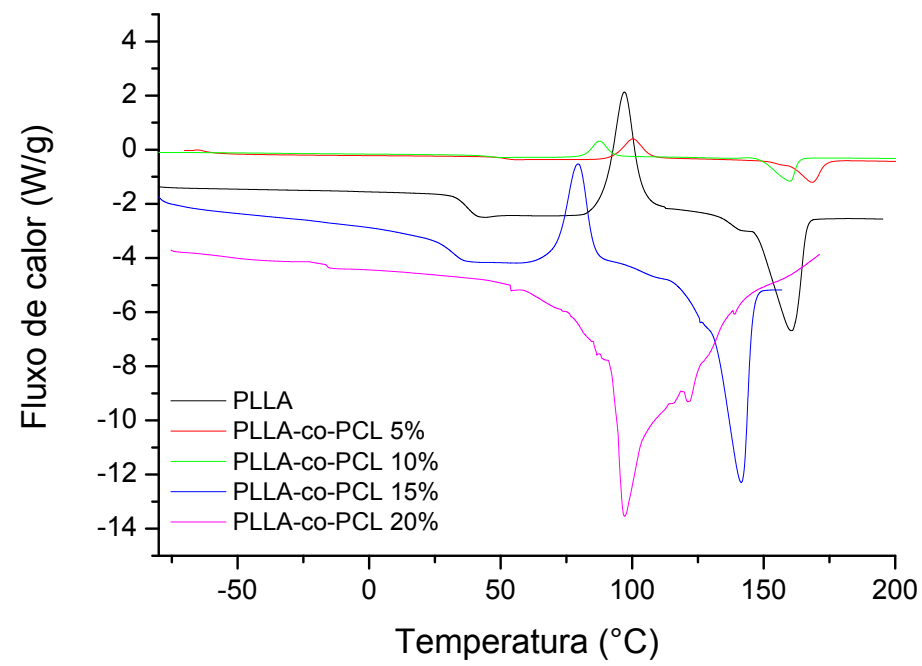

Foi observado nas análises de DSC que, apesar das amostras alimentadas com $5 \%, 10 \%$ e $15 \%$ de CL não serem copolímeros, houve uma diminuição na temperatura de transição vítrea comparando o PLLA com a amostra alimentada com 15\% de CL. Uma diminuição também foi observada quando compara-se as duas amostras. A amostra alimentada com $20 \%$ de CL, caracterizada como copolímero apresentou temperatura de fusão 


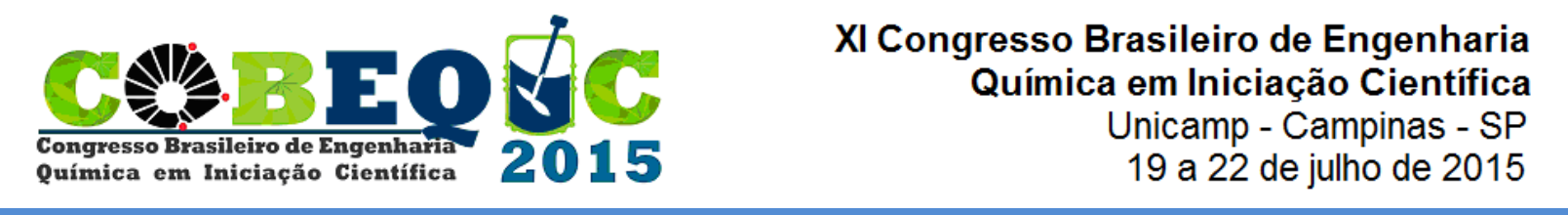

igual a $100^{\circ} \mathrm{C}$ e logo após a fusão degradou, como pode ser observado no perfil da curva de DSC.

\section{CONCLUSÃO}

A técnica de polimerização em solução, utilizando tolueno como solvente e a uma temperatura de $120^{\circ} \mathrm{C}$, é eficaz para a conversão do monômero LLA em PLLA e dos monômeros LLA e CL em P(LLA-co-CL) quando a fração mássica de CL é igual ou maior que $20 \%$. O fato de a fração alimentada de CL não ser igual a fração ligada ao LLA está relacionada com a pressão de vapor dos monômeros. Como a CL exibe maior pressão de vapor, esta volatiliza a uma temperatura mais baixa que o LLA. Assim, durante a síntese conduzida a $120^{\circ} \mathrm{C}$ a fase vapor é mais rica em PCL que o meio reacional, dificultando a interação entre os monômeros. Além disso, o LLA possui duas carbonilas no anel, enquanto que a CL apresenta apenas uma, justificando também as diferenças de reatividade, já que as carbonilas são os centros ativos da reação.

\section{REFERÊNCIAS}

BRITO, G.; AGRAWAL, P.; ARAÚJO, E.; MÉLO,T. Biopolimeros e polimeros verdes. Revista Eletrônica de Materiais e Processos, América do Sul, v.6, n.5-09, p.127-139, 2011.

LEITE. M ; FURTADO. C; COUTO.L; OLIVEIRA. F; CORREIA, Thiago. Avaliação da Biodegradação de Compósitos de Poli(E-Caprolactona)/Fibra de Coco Verde. Polímeros Ciência e Tecnologia, vol.20, n.5, p.339-344, 2010.

Liang, J.; Duan, D.; Tang, C; Tsui, C.; Chen, D. Tensile properties of PLLA/PCL composites filled with nanometer calcium carbonate. Polymer Testing, vol.32, p. 617621, 2013.

MINATA, Mauricio K. et al . Estudo da biocompatibilidade da blenda de poli(L-ácido láctico)/policaprolactona-triol. Polímeros, São Carlos, v. 23, n. 2, 2013.

Raquez, J.; Habibi, Y.; Murariu, M.; Dubois, P. Polylactide (PLA)-based nanocomposites. Progress in Polymer Science, vol.38, p.1504-1542, 2013.

TORABINEJAD, B.; MOHAMMADI-ROVSHANDEH, J.; DAVACHI, S. M.; ZAMANIAN, A. Synthesis and characterization of nanocomposite scaffolds based on triblock copolymer of $L$ lactide, E-caprolatone and nano-hydroxyapatite for bone tissue engineering. Material Science and Engineering, vol. 42, p.199-210, 2014. 